\title{
Transcultural analysis of the effectiveness of a program to promote self-regulated learning in Mozambique, Chile, Portugal, and Spain
}

Pedro Rosário, José Carlos Núñez, Luisa Trigo, Carina Guimarães, Estrella Fernández, Rebeca Cerezo, Sonia Fuentes, Marcela Orellana, América Santibáñez, Celso Fulano, Ângelo Ferreira \& Mirela Figueiredo

To cite this article: Pedro Rosário, José Carlos Núñez, Luisa Trigo, Carina Guimarães, Estrella Fernández, Rebeca Cerezo, Sonia Fuentes, Marcela Orellana, América Santibáñez, Celso Fulano, Ângelo Ferreira \& Mirela Figueiredo (2015) Transcultural analysis of the effectiveness of a program to promote self-regulated learning in Mozambique, Chile, Portugal, and Spain, Higher Education Research \& Development, 34:1, 173-187, DOI: 10.1080/07294360.2014.935932

To link to this article: http://dx.doi.org/10.1080/07294360.2014.935932

曲 Published online: 14 Aug 2014.

Lll Article views: 127

View Crossmark data \lceil
Submit your article to this journal $₫$

View related articles $₫$

Citing articles: 2 View citing articles $\widetilde{\nearrow}$ 


\title{
Transcultural analysis of the effectiveness of a program to promote self-regulated learning in Mozambique, Chile, Portugal, and Spain
}

\author{
Pedro Rosário $^{\mathrm{a} *}$, José Carlos Núñez ${ }^{\mathrm{b}}$, Luisa Trigo ${ }^{\mathrm{c}}$, Carina Guimarães ${ }^{\mathrm{d}}$, \\ Estrella Fernández $^{\mathrm{b}}$, Rebeca Cerezo ${ }^{\mathrm{b}}$, Sonia Fuentes ${ }^{\mathrm{e}}$, Marcela Orellana ${ }^{\mathrm{e}}$, \\ América Santibáñez ${ }^{\mathrm{e}}$, Celso Fulano ${ }^{\mathrm{f}}$, Ângelo Ferreira ${ }^{\mathrm{f}}$ and Mirela Figueiredo ${ }^{\mathrm{g}}$ \\ ${ }^{a}$ Department of Applied Psychology, Universidade do Minho, Braga, Portugal; ${ }^{b}$ Department \\ of Psychology, Universidad de Oviedo, Oviedo, Spain; ${ }^{c}$ Department of Psychology, \\ Universidade Católica, Porto, Portugal; ${ }^{d}$ Department of Psychology, Universidade da Beira \\ Interior, Covilhã, Portugal; ${ }^{e}$ Department of Education, Universidad Central, Santiago, \\ Chile; ${ }^{f}$ Department of Education, Universidade Pedagógica, Maputo, Mozambique; \\ ${ }^{g}$ Department of Education, Universidade Federal de São Carlos, São Carlos, Brazil
}

\begin{abstract}
The current investigation aims at assessing the effectiveness of an intervention program designed to enhance self-regulated learning (SRL) strategies at the university level, with students from different cultural, linguistic, and educational backgrounds. The central tool of the program is a set of letters in which a fictional first-year student describes his experiences as an SRL student. The program was implemented in four universities in different countries and continents (Portugal, Spain, Chile, and Mozambique), with an experimental group and a comparison group at each university (263 students from experimental groups and 247 from comparison groups). Findings display the effectiveness of the program in enhancing a set of motivational variables related to the study process and the use of SRL strategies. Data were consistent across the different cultural and academic contexts in which the program was implemented. The implications of these findings for university administrators and faculty are discussed.
\end{abstract}

Keywords: first-year experience; higher education; intervention programs; motivation; self-regulated learning; student learning; transcultural studies

\section{Introduction}

Over the past several decades, self-regulation researchers have studied how students proactively control their learning, direct, and regulate their cognition, motivation, and behavior toward their self-set goals (Zimmerman, 2002). Students who selfregulate their learning implement cognitive and metacognitive processes, before, during, and after learning (Greene, Hutchison, Costa, \& Crompton, 2012) in an attempt to control their cognition, motivation, learning environments, and behaviors (Zimmerman \& Schunk, 2011). Prior research has shown that students who receive training in self-regulated learning (SRL) strategies (e.g., goal setting, time management, and help seeking) are engaged more deeply in school tasks and show better academic achievement (Dignath, Buettner, \& Langfeldt, 2008; Rosário, González-Pienda et al., 2010; Zimmerman, 2002).

*Corresponding author. Email: prosario@psi.uminho.pt 
The primary goal of SRL instruction is to help students master three kinds of knowledge about learning strategies: declarative, procedural, and conditional (Núñez, Rosário, Vallejo, \& González-Pienda, 2013). Declarative knowledge of learning strategies is factual knowledge which involves information on a variety of learning strategies (e.g., knowing what a mind map is). The procedural knowledge of learning strategies is the knowledge of how to implement the learning strategies (e.g., know how to make a mind map). Finally, conditional knowledge is that related to when one should use a learning strategy in a particular learning context (e.g., considering that a mind map is a time-consuming strategy, students must decide when the use of this strategy might or might not be effective) (Alexander, 2006). Hands-on practice with a set of SRL strategies (see Rosário et al., 2010; Weinstein, Husman, \& Dierking, 2000; Zimmerman \& Martínez-Pons, 1986) will help students become more aware of their agent role as learners, and to effectively focus their attention on the contents to be learned (Rosário et al., 2007; Weinstein et al., 2000).

In spite of the importance of SRL competency, many university students lack in these abilities (Fernández et al., 2013) and frequently struggle to evaluate and adjust their learning strategies when facing difficulties in their academic work (Weinstein et al., 2000). This type of SRL 'malfunction' often results in poor optimization of the training and learning possibilities provided by educational institutions, and, consequently, in low academic performance.

In fact, although the literature recurrently underlines the relationship between explicitly teaching SRL strategies and achieved academic outcomes (Cleary \& Chen, 2009; Núñez, Cerezo et al., 2011; Rosário et al., 2010), universities usually do not deliver explicit training on SRL strategies to first-year university students (Rosário et al., 2007; Simpson, Hynd, Nist, \& Burrel, 1997; Weinstein et al., 2000).

Considering the international call to improve SRL competencies in university students (see Hattie, Biggs, \& Purdie, 1996; Rosário et al., 2010; Simpson et al., 1997), it is important to collect data on the efficacy of programs that are appropriate for this population. To this end, the present study compared differences among university students, from four different countries, who participated in an international research project to improve SRL competencies.

\section{Purpose of the study}

The main goal of the current investigation is to assess the efficacy of the program 'Letters from Gervase' in improving SRL competences and promoting learning autonomy among university students, regardless of their academic culture or the geographic location of the program (in the current study, the program was implemented in Mozambique, Chile, Portugal, and Spain).

This program has already been tested and proven efficient in promoting SRL competences of first-year university students from Portugal and Spain (Núñez et al., 2011; Rosário et al., 2007, 2010). Our aim in the present study was to extend the program to students from four different academic settings and compare the data obtained across these four countries (Mahrous \& Ahmed, 2010).

For this reason, and taking as reference the results obtained in previous studies using this intervention program (Núñez et al., 2011; Rosário et al., 2007, 2010), a pre- and post-design with comparison groups was run at universities from the four noted countries. It is expected that (a) after the intervention program, students from the experimental groups, compared to students from the comparison groups, will show higher 
levels of reported use of SRL strategies, higher levels of structural complexity when dealing with a task, and report more self-efficacy for SRL and higher perceived instrumentality of the use of SRL strategies, and (b) the post-test differences in these variables will show the same tendency in all four countries (cross-cultural consistency).

\section{Method}

\section{Context of the study}

This investigation was carried out in four universities of different countries and continents. Two of them were Portuguese and the other two Spanish-speaking countries. In Europe, it was carried out at the University of Minho (Braga, Portugal) and at the University of Oviedo (Oviedo, Spain). In South America, the program was applied at the Central University of Chile (Santiago, Chile) and in Africa, at the Pedagogical University of Mozambique (Maputo, Mozambique).

\section{Participants}

First-year students were selected as a focus group for this intervention because the promotion of SRL strategies and how to manage and control the study process in the first year of university can help novice students in meeting university demands and, therefore, foster students' retention (Greene et al., 2012). To enable the comparison of obtained results, the four intervention programs followed the same criteria in the selection of the samples, and same guidelines for running the sessions. In each university, all first-year students were invited to participate in the study. The volunteers who agreed to participate were randomly assigned to the program or comparison group.

In the University of Minho (Portugal), 117 first-year university students participated in the study: 55 of the students were enrolled in the experimental group, with an age range of $17-21$ years $(M=18.31, \mathrm{SD}=0.84)$, and 62 students in the comparison group, with an age range of $17-44$ years $(M=19.06, \mathrm{SD}=3.7)$. In the University of Oviedo (Spain), 108 first-year university students participated in the study: 66 students were enrolled in the experimental group (age range of $17-27$ years $(M=19.36, \mathrm{SD}=$ $1.82)$ ), and 42 in the comparison group (age range of 18-39 years $(M=20.64, \mathrm{SD}=$ 3.72)). In the Central University (Chile), 157 first-year university students participated in the study: 75 students were enrolled in the experimental group (age range of 17-21 years $(M=18.28, \mathrm{SD}=0.80)$ ), and 76 in the comparison group (age range of 17-44 years $(M=18.96, \mathrm{SD}=3.38)$ ). In the Pedagogical University (Mozambique), 144 first-year university students participated in the study: 77 of the students were enrolled in the experimental group (age range of $17-23$ years $(M=18.45, \mathrm{SD}=1.08)$ ), and 67 students in the comparison group (age range of $17-44$ years $(M=19.03, \mathrm{SD}=3.34)$ ). More information is provided in Table 1.

\section{Description of the program 'Letters from Gervase'}

The 'Gervase letters' intervention program is a tool intended to train university students in SRL strategies, especially first-year students (Rosário et al., 2007, 2010). The program is rooted in the model 'PEA: planning, execution, and assessment' (Rosário et al., 2007, 2010) based on the social cognitive model of Zimmerman (2002, 2008).

At the core of the tool are a series of 13 texts, drafted as letters written by a first-year student Gervase (Rosário, Núñez, \& González-Pienda, 2006). In these texts, Gervase 
Table 1. Participants' demographics: gender by country and group condition type.

\begin{tabular}{llccllcc}
\hline & \multicolumn{3}{c}{ Experimental group } & & \multicolumn{3}{c}{ Comparison group } \\
\cline { 2 - 3 } & Men $n /(\%)$ & Women $n /(\%)$ & Total $n$ & & Men $n /(\%)$ & Women $n /(\%)$ & Total $n$ \\
\hline UM-PT & $21(38.2)$ & $34(61.8)$ & 55 & & $24(38.7)$ & $38(61.3)$ & 62 \\
UO-ES & $22(33.3)$ & $44(66.7)$ & 66 & & $13(31)$ & $29(69)$ & 42 \\
UC-CL & $27(36)$ & $48(64)$ & 75 & & $30(39.5)$ & $46(60.5)$ & 76 \\
UP-MZ & $23(29.9)$ & $54(70.1)$ & 77 & & $20(29.9)$ & $47(70.2)$ & 67 \\
\hline
\end{tabular}

Note: UM-PT (University of Minho, Portugal); UO-ES (University of Oviedo, Spain); UC-CL (Central University, Chile); UP-MZ (Pedagogical University, Mozambique).

describes his own experiences as a university first-year student and reflects upon the SRL processes, academic adaptation process, and other challenges he is facing. Each letter is organized around a repertoire of learning strategies set by Zimmerman and Martínez-Pons in 1986 (e.g., goal setting, organization and transformation of information, taking notes, and information seeking), corresponding to the three phases of the SRL process (e.g., forethought phase, performance phase, and self-reflection phase) (Zimmerman, 2002) (see Table 1). Within the social cognitive framework, students can learn vicariously by observing how other people behave (Schunk, 1996) and by analyzing the positive or negative results of their acts. It is thus assumed that not all learning emerges from direct practice (Pintrich \& Schunk, 2002) and also that the observation of a model, especially when the model is also a student experiencing the same academic challenges, can guide the training of competences, attitudes, beliefs, and self-regulated behavior (Rosário et al., 2010). Moreover, this story-based tool was designed to promote students' analysis, of the contents of the letters, followed by the discussion of the embedded SRL strategies with the help of a tutor. For example, during the sessions, the participants discussed their declarative, procedural, and conditional knowledge regarding the SRL strategies (see Table 1) (e.g., self-evaluations concerning time management, note-taking strategies in class, discussion and comparison of the distracters when studying at home, challenges of writing an assignment, and control of text anxiety).

This inductive methodology makes it easier for students to work autonomously and fosters a deep approach toward the texts. University students are invited to analyze the stories told in the letters to extract the information considered as relevant and relate it to their own experiences as students. Working with this story-based tool provides students with the opportunity to reflect on their own learning processes, both at an individual and at a group level, with hopes of fostering student motivation and academic engagement.

\section{Procedure}

The four participating universities executed the program following the exact same design. The 'letters from Gervase' program was implemented in the first academic semester, on a weekly basis, during after-school hours (90 minutes for each of the six sessions). The researchers at the four universities agreed on the six letters to be used (see Table 2) (Rosário et al., 2006) and within each session followed set structured activities as follows: (1) each student read the assigned letter individually (approximately 10-15 minutes); (2) for the next 45 minutes, the students exchanged ideas 
Table 2. Distribution of the contents and SRL strategies addressed in the intervention program (selection for the present investigation).

\begin{tabular}{|c|c|}
\hline Distribution of the letters in the sessions & Contents and SRL strategies addressed \\
\hline \multicolumn{2}{|l|}{ Letter 1/Session 1} \\
\hline \multirow{3}{*}{$\begin{array}{l}\text { (...) Ultimately, what does adapting to the } \\
\text { university mean? }\end{array}$} & 1. Adapting to the university \\
\hline & 2. Planning and management of study time. \\
\hline & $\begin{array}{l}\text { 3. Reflection on the learning process and the } \\
\text { student's role in it }\end{array}$ \\
\hline \multicolumn{2}{|l|}{ Letter 2/Session 2} \\
\hline \multirow{3}{*}{$\begin{array}{l}\text { (...) What are my goals? What } \\
\text { really guides my behavior at all levels? } \\
\text { (i.e., studies, sports, friends) }\end{array}$} & $\begin{array}{l}\text { 1. Establishing goals (specific, realistic, and } \\
\text { assessable) }\end{array}$ \\
\hline & 2. Long- and short-term goals \\
\hline & 3. Learning goals and achievement goals \\
\hline \multicolumn{2}{|l|}{ Letter 3/Session 3} \\
\hline \multirow[t]{4}{*}{ (... ) How can I improve my grades? } & $\begin{array}{l}\text { 1. Information organization: summaries, tables, } \\
\text { outlines, and conceptual maps }\end{array}$ \\
\hline & 2. Note-taking strategies \\
\hline & 3. Time optimization \\
\hline & 4. Controlling distracters \\
\hline \multicolumn{2}{|l|}{ Letter $4 /$ Session 4} \\
\hline \multirow{3}{*}{$\begin{array}{l}\text { (... ) Gervase, do you know how to } \\
\text { overcome procrastination? }\end{array}$} & 1. Planning tasks \\
\hline & 2. Organization of study environment \\
\hline & 3. Control of internal and external distracters \\
\hline \multicolumn{2}{|l|}{ Letter $5 /$ Session 5} \\
\hline (... ) Who controls your learning? Do you & 1. SRL \\
\hline \multirow{2}{*}{$\begin{array}{l}\text { know how to distinguish academically } \\
\text { successful students? }\end{array}$} & $\begin{array}{l}\text { 1.1. Cyclical model of SRL (planning, } \\
\text { performance, and assessment) }\end{array}$ \\
\hline & $\begin{array}{l}\text { 1.2. Learning competences (establishing goals, } \\
\text { study planning and management, control } \\
\text { of procrastination, structuring the } \\
\text { environment, monitoring, and study } \\
\text { strategies) }\end{array}$ \\
\hline \multirow{3}{*}{$\begin{array}{l}\text { Letter 6/Session } 6 \\
\text { (...) What is anxiety? What can you do } \\
\text { about anxiety? }\end{array}$} & \\
\hline & 1. Aspects of anxiety (feelings and emotions) \\
\hline & $\begin{array}{l}\text { 1.1. Text anxiety } \\
\text { 1.2. Relaxation techniques }\end{array}$ \\
\hline
\end{tabular}

and solved the problems posed in the letters, in small groups to promote team work; (3) then, for about 20 minutes, each group of students presented their ideas and conclusions to the rest of the class; (4) in the last 10 minutes of each session, the tutor, who guided the session, presented a brief summary of the main topics that were discussed. In each university all the participants (experimental and comparison groups) were gathered immediately before and after the implementation of the program to complete the assessment instruments. The local tutors ran these assessment sessions which lasted approximately 40 minutes each.

Principal researchers in each country (senior investigators in Portugal and Spain and post-doctoral researchers in Chile and Mozambique) helped the tutors to follow the set guidelines, aiming to guarantee that the application of conditions and methodologies conducted in all sessions were as similar as possible. During the implementation of the program, on a weekly basis, the principal researchers in each country sent a brief report to all the members enrolled in the investigation describing the set activities conducted, their impact on students, and a brief overall evaluation of the session. The tutors 
who guided the sessions were postgraduates in the area of self-regulation of learning processes and held bimonthly meetings by Skype throughout the academic semester to set and monitor the program application (e.g., discuss the topics/learning strategies to highlight in each session, prepare brief summaries, and share best educational practices).

\section{Measures and instruments}

Knowledge of SRL strategies. Knowledge of SRL strategies was assessed by means of the SRL Strategies Questionnaire (Rosário et al., 2007; Rosário, Núñez et al., 2010), a 10-item questionnaire with three response options, from which students were requested to choose the correct one (there is only one correct option). The questionnaire was focused on the SRL strategies that are addressed during the intervention (e.g., an effective note-taking strategy to study and prepare exams, such as (a) write literally what the teacher says in class; (b) copy the 'best' student's journals and notes; and (c) write the most important topics discussed in class and complete them at home with other information). Cronbach's alpha of the total scale was 0.89 .

SRL strategies. The SRL strategies inventory (Rosário et al., 2007; Rosário, Núñez et al., 2010) is a nine-item instrument representing the three phases of the SRL process: Planning (e.g., 'I make a plan before I begin writing. I think about what I want to say and how I need to write it.'), Execution (e.g., 'If I become distracted or lose concentration while I am in class or studying, then I usually try to regain my concentration to achieve my goals.'), and Evaluation (e.g., 'I compare the grades I receive with the goals I set for that subject.'). The items were rated on a five-point Likert scale ranging from 1 (never) to 5 (always) ( $\operatorname{Min}=12$, Max $=60$ ). Cronbach's alpha of the total scale was 0.87 .

Structural complexity of the learning outcomes. To assess the quality of the learning process, we analyzed the structural complexity of the students' responses to a specific activity. The task (see Rosário et al., 2007) was adapted from Biggs and Collis (1982), and the students' written texts were classified according to the SOLO (Structures of the observed learning outcome) taxonomy of Biggs and Collis (1982). This taxonomy describes five levels of the structured organization of the task from incompetence to expertise in a hierarchical sequence. Each of the SOLO levels relates to a qualitatively different mode of engagement with a task as follows: prestructural (lowest level), unistructural, multistructural, relational, and extended abstract (highest level) (Biggs \& Collis, 1982). The first three SOLO levels were grouped into a category called surface (represented by a value of one) and the next two (relational and expanded abstraction) into a category called deep (represented by a value of two). The responses provided by the students in the task were appraised and classified by three judges (with $87 \%$ inter-rater agreement).

Self-efficacy for SRL. Student self-efficacy for SRL assesses students' belief in their capabilities in regulating their own learning by using a variety of learning strategies (Rosário et al., 2007; Rosário, Núñez et al., 2010). The 10 items that assess student self-efficacy for SRL begin with the phrase, 'How well can you ...' and were completed with statements such as ' ... take notes and later elaborate upon them to learn the material in detail' or '.. use strategies to comprehensively memorize the study material'. These items were rated on a five-point Likert scale ranging from 1 (not very well) to 5 (very well). Cronbach's alpha of the total scale was 0.89 . 
Perceived instrumentality of the SRL strategies. Instrumentality or perceived utility of the strategies for SRL in the academic context was also assessed by means of a 10-item questionnaire. The 10 items begin with the phrase, 'How useful do you think it is to...' and were completed with statements such as '... take notes and later elaborate upon them to learn the material in detail' or ' ... use strategies to comprehensively memorize the study material'. The items are presented using a five-point Likert scale ranging from 1 (not very useful) to 5 (very useful). Cronbach's alpha of the total scale was 0.91 .

\section{Data analysis}

This study had two aims. Firstly, to examine the effects of the intervention program in each of the four countries, several ANCOVAs were performed. The dependent variables were the structural complexity of students' responses to a task, the self-efficacy for SRL, the reported use of SRL strategies, and the perceived instrumentality of the use of SRL strategies. As covariates for this first objective, we used the initial (pretest) level of each one of the dependent variables (to statistically control for the effect of possible pre-test group differences, since the participants had not been randomly assigned to the groups): the declarative knowledge of SRL strategies - to use a learning strategy, it is important to have the declarative knowledge of it, and such knowledge can interact with the dependent variables, distorting the results, the age, and the gender of students. Secondly, this study also sought to examine whether the intervention program was equally effective regardless of the country of application. To do this, new ANCOVAs were conducted which included country as a new covariate (thus controlling statistically for the effect of this variable and, in turn, determining whether it should be taken into account in the assessment of the effect size of the intervention program).

\section{Results}

\section{Analysis of the effectiveness of the intervention program in each country}

The descriptive statistics of the pre- and post-test measures of each variable for experimental and comparison groups of all four universities are shown in Table 3. The results of the ANCOVAs are shown in Table 4.

The results suggest that the pre-test level of the dependent variables is the only covariate that shows a statistically significant effect on their post-test levels. This is true whether we analyze the results for each country independently (see Table 4), or for the total sample (see Table 5). After controlling for covariates (initial pre-test levels in the reported use of SRL strategies, declarative knowledge of SRL strategies, gender, and age), results obtained in the reported use of SRL strategies were consistent with our first hypothesis. The results reflect statistically significant group differences at post-test in each country, always favoring the experimental group: Mozambique, $F(1$, $138)=14.89, p<0.001, \eta_{p}^{2}=0.09$; Chile, $F(1,145)=17.80, p<0.001, \eta_{p}^{2}=0.11$; Portugal, $F(1,111)=23.80, p<0.001, \eta_{p}^{2}=0.18$; and Spain, $F(1,102)=9.22, p<$ $0.001, \eta_{p}^{2}=0.10$. Applying the criteria of the classic work of Cohen (1988), in which an $\eta_{p}^{2}=0.010$ (equivalent to Cohen's $d=0.20$ ) indicates a small effect size, an $\eta_{p}^{2}=0.059$ (equivalent to Cohen's $d=0.50$ ) indicates a medium effect size, and an $\eta_{p}^{2}=0.138$ (equivalent to Cohen's $d=0.80$ ) indicates a large effect size, it was 
Table 3. Descriptive statistics of the variables used in the investigation by assessment time (pre-test and post-test) and sample (four countries).

\begin{tabular}{|c|c|c|c|c|c|c|c|c|}
\hline & \multicolumn{4}{|c|}{ Experimental group } & \multicolumn{4}{|c|}{ Comparison group } \\
\hline & \multicolumn{2}{|c|}{ Pre-test } & \multicolumn{2}{|c|}{ Post-test } & \multicolumn{2}{|c|}{ Pre-test } & \multicolumn{2}{|c|}{ Post-test } \\
\hline & $M$ & SD & $M$ & SD & $M$ & SD & $M$ & SD \\
\hline \multicolumn{9}{|l|}{ Portugal } \\
\hline SRL knowledge & 7.85 & 1.46 & 8.33 & 1.14 & 7.77 & 1.40 & 7.61 & 1.28 \\
\hline SRL strategies & 42.75 & 5.85 & 45.36 & 5.49 & 42.60 & 5.72 & 42.21 & 5.87 \\
\hline SOLO & 1.07 & 0.26 & 1.76 & 0.43 & 1.37 & 0.49 & 1.32 & 0.47 \\
\hline SRL self-efficacy & 36.73 & 5.12 & 37.80 & 5.47 & 36.48 & 4.75 & 35.50 & 4.48 \\
\hline SRL instrumentality & 43.13 & 4.15 & 43.58 & 4.39 & 43.34 & 5.04 & 42.70 & 4.88 \\
\hline \multicolumn{9}{|l|}{ Spain } \\
\hline SRL knowledge & 7.56 & 1.19 & 8.23 & 1.26 & 7.52 & 1.45 & 7.55 & 1.56 \\
\hline SRL strategies & 41.97 & 7.01 & 45.14 & 5.61 & 44.33 & 5.23 & 43.24 & 6.03 \\
\hline SOLO & 1.02 & 0.12 & 1.56 & 0.50 & 1.29 & 0.46 & 1.24 & 0.43 \\
\hline SRL self-efficacy & 36.85 & 4.28 & 39.92 & 4.96 & 37.47 & 4.97 & 37.49 & 3.33 \\
\hline SRL instrumentality & 44.11 & 4.41 & 43.94 & 5.04 & 43.49 & 4.06 & 42.05 & 5.92 \\
\hline \multicolumn{9}{|l|}{ Chile } \\
\hline SRL knowledge & 7.85 & 1.42 & 8.37 & 1.10 & 7.75 & 1.38 & 7.55 & 1.29 \\
\hline SRL strategies & 42.84 & 5.96 & 45.08 & 5.69 & 42.43 & 5.89 & 42.21 & 6.16 \\
\hline SOLO & 1.07 & 0.25 & 1.79 & 0.41 & 1.36 & 0.48 & 1.33 & 0.47 \\
\hline SRL self-efficacy & 36.61 & 5.29 & 37.69 & 5.72 & 36.21 & 4.78 & 35.33 & 4.46 \\
\hline SRL instrumentality & 43.15 & 4.13 & 45.24 & 3.82 & 43.16 & 5.14 & 42.34 & 4.85 \\
\hline \multicolumn{9}{|l|}{ Mozambique } \\
\hline SRL knowledge & 7.90 & 1.52 & 8.27 & 1.38 & 7.79 & 1.30 & 7.78 & 1.37 \\
\hline SRL strategies & 42.13 & 6.21 & 46.58 & 5.84 & 42.61 & 7.67 & 43.58 & 6.54 \\
\hline SOLO & 1.09 & 0.29 & 1.70 & 0.46 & 1.28 & 0.45 & 1.36 & 0.48 \\
\hline SRL self-efficacy & 37.01 & 5.59 & 39.25 & 6.04 & 37.09 & 4.93 & 36.97 & 5.27 \\
\hline SRL instrumentality & 43.86 & 3.90 & 45.88 & 3.89 & 43.69 & 5.44 & 43.35 & 5.26 \\
\hline \multicolumn{9}{|l|}{ Total sample } \\
\hline SRL knowledge & 7.81 & 1.46 & 8.19 & 1.31 & 7.72 & 1.31 & 7.79 & 1.32 \\
\hline SRL strategies & 42.85 & 5.91 & 45.30 & 5.82 & 42.40 & 6.58 & 43.26 & 6.15 \\
\hline SOLO & 1.11 & 0.32 & 1.66 & 0.47 & 1.26 & 0.44 & 1.39 & 0.49 \\
\hline SRL self-efficacy & 36.91 & 5.27 & 38.16 & 5.46 & 36.65 & 4.68 & 36.89 & 5.11 \\
\hline SRL instrumentality & 43.42 & 4.04 & 44.53 & 4.58 & 43.56 & 5.01 & 43.06 & 4.99 \\
\hline
\end{tabular}

Notes: SRL knowledge = declarative knowledge of self-regulated learning strategies (Max. 10 and Min. 0); SRL use $=$ use of self-regulated learning strategies (Max. 60 and Min. 12); SOLO = structural complexity of the products (Max 2 and Min. 1); SRL self-efficacy = self-efficacy to self-regulate learning process (Max 50 and Min. 10); SRL instrumentality = perceived instrumentality of the use of self-regulated learning strategies (Max 50 and Min. 10).

concluded that the effect size is important in all four countries (medium in Spain, Chile, and Mozambique and large in Portugal; see Figure 1).

With regard to the structural complexity of students' responses to the proposed task (SOLO), the group differences obtained in each country were also statistically significant (favoring the experimental group): Mozambique , $F(1,138)=16.27, p<0.001$, $\eta_{p}^{2}=0.11$; Chile, $F(1,145)=38.61, p<0.001, \eta_{p}^{2}=0.21$; Portugal, $F(1,111)=$ $27.24, p<0.001, \eta_{p}^{2}=0.20$; and Spain, $F(1,102)=20.14, p<0.001, \eta_{p}^{2}=0.17$. As in the case of the first dependent variable analyzed, the effect size was also important for SOLO (medium for Mozambique and large for Spain, Portugal, and Chile; see Figure 1). 
Table 4. Post-test group difference (by sample and countries) in the dependent variables (ANCOVAs).

\begin{tabular}{|c|c|c|c|c|c|c|c|c|c|c|c|c|}
\hline & \multicolumn{3}{|c|}{ Portugal } & \multicolumn{3}{|c|}{ Spain } & \multicolumn{3}{|c|}{ Chile } & \multicolumn{3}{|c|}{ Mozambique } \\
\hline & $F(1,111)$ & $P$ & $\eta_{p}^{2}$ & $F(1,102)$ & $p$ & $\eta_{p}^{2}$ & $F(1,145)$ & $p$ & $\eta_{p}^{2}$ & $F(1,138)$ & $p$ & $\eta_{p}^{2}$ \\
\hline \multicolumn{13}{|l|}{ SRL use } \\
\hline Pre-test level of SRL use $e^{\mathrm{a}}$ & 230.04 & 0.000 & 0.67 & 49.54 & 0.000 & 0.33 & 236.99 & 0.000 & 0.62 & 51.56 & 0.000 & 0.27 \\
\hline SRL knowledge & 0.06 & 0.630 & 0.00 & 2.19 & 0.142 & 0.02 & 0.07 & 0.797 & 0.00 & 0.37 & 0.542 & 0.00 \\
\hline Gender $^{\mathrm{a}}$ & 2.42 & 0.123 & 0.02 & 0.23 & 0.631 & 0.00 & 0.71 & 0.401 & 0.01 & 1.96 & 0.163 & 0.01 \\
\hline$A g e^{\mathrm{a}}$ & 0.20 & 0.655 & 0.00 & 0.54 & 0.465 & 0.01 & 0.15 & 0.697 & 0.00 & 0.66 & 0.419 & 0.00 \\
\hline Group $(E G-C G)$ & 23.80 & 0.000 & 0.18 & 9.22 & 0.001 & 0.10 & 17.80 & 0.000 & 0.11 & 14.89 & 0.000 & 0.09 \\
\hline \multicolumn{13}{|l|}{ SOLO } \\
\hline Pre-test SOLO level & 1.18 & 0.279 & 0.01 & 3.95 & 0.050 & 0.04 & 0.95 & 0.330 & 0.01 & 0.01 & 0.941 & 0.00 \\
\hline SRL knowledge $e^{\mathrm{a}}$ & 8.60 & 0.004 & 0.07 & 0.00 & 0.981 & 0.00 & 10.13 & 0.002 & 0.07 & 6.16 & 0.014 & 0.04 \\
\hline Gender ${ }^{\mathrm{a}}$ & 1.94 & 0.167 & 0.02 & 0.42 & 0.517 & 0.00 & 3.42 & 0.066 & 0.02 & 0.15 & 0.695 & 0.00 \\
\hline$A g e^{\mathrm{a}}$ & 0.88 & 0.351 & 0.01 & 8.15 & 0.005 & 0.07 & 0.72 & 0.398 & 0.01 & 0.05 & 0.818 & 0.00 \\
\hline Group $(E G-C G)$ & 27.24 & 0.000 & 0.20 & 20.14 & 0.000 & 0.17 & 38.61 & 0.000 & 0.21 & 16.27 & 0.000 & 0.11 \\
\hline \multicolumn{13}{|l|}{ SRL self-efficacy } \\
\hline Pre-test level of SRL self-efficacy ${ }^{\mathrm{a}}$ & 193.25 & 0.000 & 0.64 & 30.19 & 0.000 & 0.23 & 258.80 & 0.000 & 0.64 & 73.24 & 0.000 & 0.35 \\
\hline SRL knowledge & 0.07 & 0.788 & 0.00 & 1.06 & 0.305 & 0.01 & 0.66 & 0.418 & 0.01 & 0.15 & 0.702 & 0.00 \\
\hline Gender ${ }^{\mathrm{a}}$ & 0.02 & 0.885 & 0.00 & 0.06 & 0.802 & 0.00 & 0.85 & 0.359 & 0.01 & 25.23 & 0.000 & 0.16 \\
\hline$A g e^{\mathrm{a}}$ & 0.07 & 0.875 & 0.00 & 1.26 & 0.265 & 0.01 & 0.08 & 0.784 & 0.00 & 2.85 & 0.093 & 0.02 \\
\hline Group $(E G-C G)$ & 14.06 & 0.000 & 0.11 & 9.30 & 0.001 & 0.11 & 16.58 & 0.000 & 0.10 & 16.48 & 0.003 & 0.06 \\
\hline \multicolumn{13}{|l|}{ SRL instrumentality } \\
\hline Pre-test level of SRL instrumentality ${ }^{\mathrm{a}}$ & 58.26 & 0.000 & 0.34 & 20.86 & 0.000 & 0.17 & 51.15 & 0.000 & 0.26 & 56.59 & 0.000 & 0.29 \\
\hline SRL knowledge $\mathrm{a}^{\mathrm{a}}$ & 0.31 & 0.579 & 0.00 & 0.10 & 0.748 & 0.00 & 0.33 & 0.567 & 0.00 & 0.95 & 0.332 & 0.01 \\
\hline Gender ${ }^{\mathrm{a}}$ & 0.53 & 0.470 & 0.01 & 0.31 & 0.580 & 0.00 & 2.36 & 0.127 & 0.02 & 2.61 & 0.109 & 0.02 \\
\hline$A g e^{\mathrm{a}}$ & 0.79 & 0.375 & 0.01 & 0.06 & 0.813 & 0.00 & 1.33 & 0.252 & 0.01 & 2.17 & 0.143 & 0.02 \\
\hline Group $(E G-C G)$ & 2.39 & 0.125 & 0.02 & 1.44 & 0.233 & 0.01 & 23.60 & 0.000 & 0.14 & 17.86 & 0.000 & 0.12 \\
\hline
\end{tabular}

Notes: SRL knowledge = declarative knowledge of self-regulated learning strategies (Max. 10 and Min. 0); SRL = use of self-regulated learning strategies (Max. 60 and Min 12); SOLO = structural complexity of the products (Max. 2 and Min. 1); SRL Self-efficacy = self-efficacy to self-regulate learning process (Max. 50 and Min. 10); SRL Instrumentality = perceived instrumentality of the use of self-regulated learning strategies (Max. 50 and Min. 10). EG (experimental group); CG (comparison group).

${ }^{\mathrm{a} C}$ Covariates. 
Table 5. Results of ANCOVAs with country as a covariate.

\begin{tabular}{|c|c|c|c|c|}
\hline & $F(1 / 513)$ & $p$ & $\eta_{p}^{2}$ & $R^{2}$ \\
\hline SRL strategies & & & & 0.439 \\
\hline Pre-test level of SRL use* & 354.206 & 0.000 & 0.408 & \\
\hline SRL knowledge* & 0.824 & 0.364 & 0.002 & \\
\hline Gender* & 4.230 & 0.040 & 0.008 & \\
\hline Age* & 0.009 & 0.924 & 0.000 & \\
\hline Country* & 7.142 & 0.008 & 0.014 & \\
\hline Treatment Group (EG-CG) & 19.955 & 0.000 & 0.037 & \\
\hline SOLO & & & & 0.098 \\
\hline Pre-test level of SOLO* & 0.208 & 0.648 & 0.000 & \\
\hline SRL knowledge* & 17.717 & 0.000 & 0.033 & \\
\hline Gender* & 1.383 & 0.240 & 0.003 & \\
\hline$A g e^{*}$ & 0.663 & 0.416 & 0.001 & \\
\hline Country* & 0.087 & 0.768 & 0.000 & \\
\hline Treatment Group (EG-CG) & 35.044 & 0.000 & 0.064 & \\
\hline SRL Self-Efficacy & & & & 0.490 \\
\hline Pre-test level of SRL Self-Efficacy* & 398.974 & 0.000 & 0.437 & \\
\hline SRL knowledge* & 0.437 & 0.509 & 0.001 & \\
\hline Gender* & 39.363 & 0.000 & 0.071 & \\
\hline Age* & 0.000 & 0.999 & 0.000 & \\
\hline Country* & 2.694 & 0.101 & 0.005 & \\
\hline Treatment Group $(E G-C G)$ & 15.839 & 0.000 & 0.030 & \\
\hline SRL Instrumentality & & & & 0.294 \\
\hline Pre-test level of SRL Instrumentality* & 181.271 & 0.000 & 0.261 & \\
\hline SRL knowledge* & 0.337 & 0.562 & 0.001 & \\
\hline Gender* & 1.554 & 0.213 & 0.003 & \\
\hline Age* & 0.123 & 0.726 & 0.000 & \\
\hline Country* & 1.184 & 0.277 & 0.002 & \\
\hline Treatment Group (EG-CG) & 19.281 & 0.000 & 0.036 & \\
\hline
\end{tabular}

Note: Sample of experimental group $(n=249)$; sample of comparison group $(n=271)$.

* Significance at 0.001 .

The results obtained in perceived efficacy for SRL also revealed statistically significant group differences (favoring the experimental groups) in all four samples: Mozambique, $F(1,138)=16.48, p=0.003, \eta_{p}^{2}=0.06$; Chile, $F(1,145)=16.58, p<$ $0.001, \eta_{p}^{2}=0.10$; Portugal, $F(1,111)=14.06, p<0.001, \eta_{p}^{2}=0.11$; and Spain, $F(1$, $102)=9.30, p<0.001, \eta_{p}^{2}=0.11$. The effect size was medium in the samples of Portugal, Spain, and Chile, but small for Mozambique (see Figure 1).

Lastly, with regard to perceived instrumentality, analysis of the group differences yielded statistically significant differences for two of the samples: Mozambique, $F(1,138)=17.86, p<0.001, \eta_{p}^{2}=0.12$, and Chile, $F(1,145)=23.60, p<0.001$, $\eta_{p}^{2}=0.14$, with a medium and large effect size, respectively, but not for the Spanish or the Portuguese samples (see Figure 1).

\section{Country effect on the results of the intervention program}

ANCOVA results are presented in Table 5. These data indicate a significant main effect of the variable country for the use of SRL strategies, $F(1,513)=7.142, p=0.008$, $\eta_{p}^{2}=0.014$, with small effect size ( $1.4 \%$ of variance explained). The main effects were not statistically significant for the structural complexity of students' responses 


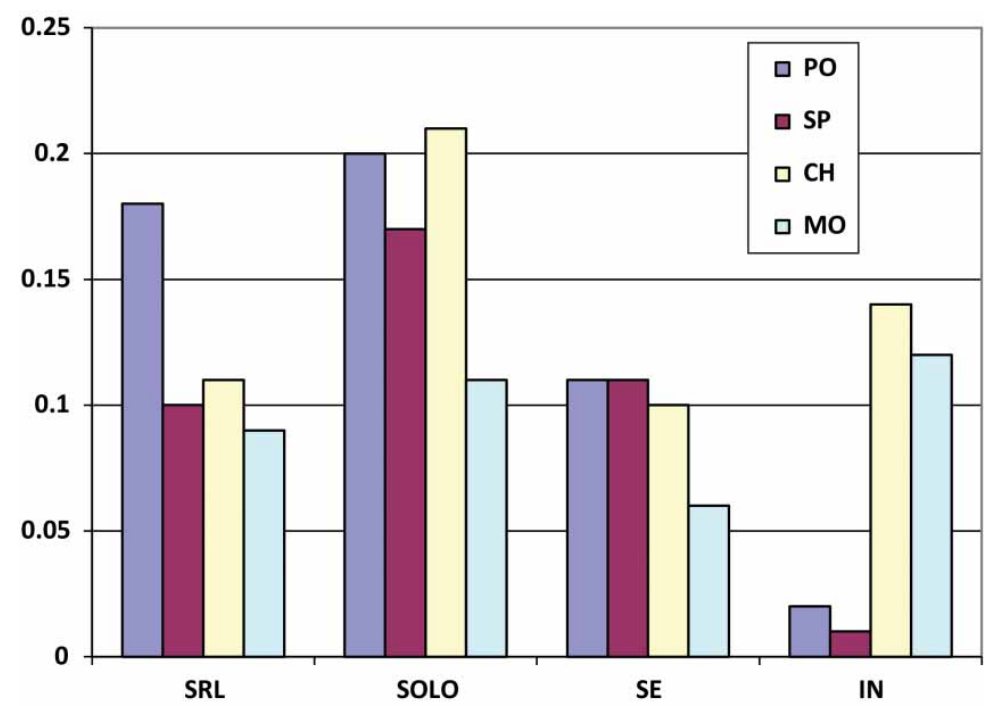

Figure 1. Comparison of effect size for intervention in four countries.

Note: PO (Portugal); SP (Spain); CH (Chile); MO (Mozambique); SRL; SOLO; SE (Self-Efficacy); IN (SRL instrumentality).

to the proposed task (SOLO), for the perceived efficacy for SRL, and for the perceived instrumentality. These data suggest that including country within the predictive model is not relevant. Additionally, note that age is not associated with statistical differences in the post-test, whereas gender does seem to be a variable that should be taken into account when considering the use of SRL strategies and SRL self-efficacy. Finally, as indicated previously, most of the differences in the post-test are associated with the levels of the dependent variables prior to intervention (pre-test level), except for SOLO.

In summary, after controlling statistically for the effect of covariates, particularly the country in which the program was run, the data indicate that the intervention program was effective (see Table 5). However, as discussed in the limitations section of this paper, when discussing the effect size of the intervention, the duration (three and half months in our case) and the nature of 'variable assessment' (except for SOLO, data were collected with self-report) should be taken into account.

\section{Discussion}

Findings show that the program 'Letters from Gervase' was efficacious both in promoting the use of SRL strategies and in improving the motivational variables directly related to the study process, especially the self-efficacy for SRL. Further, as we dealt with groups of first-year students from different geographic and academic settings, the results showed a clear stability of the program efficacy not only with samples of students from similar (e.g., Portugal and Spain), but also with samples of students from different academic settings (e.g., Spain and Mozambique).

Specifically, after the intervention, statistically significant group differences were found in all enrolled samples concerning self-reported use of SRL strategies (favoring 
the experimental groups). These results reinforce the idea that the competences of SRL can be improved by means of appropriate training (Núñez, Rosário, Vallejo, \& González-Pienda, 2013), even when the number of sessions are limited, as in this case. Additionally, in order to obtain an observed measure of the students' cognitive engagement (Boekaerts \& Corno, 2005), we assessed the structural complexity of students' responses to a specific task using the SOLO taxonomy. The results indicated increasing levels of conceptual complexity in the students' written texts at the end of the program (experimental groups). Data corroborate students' higher level of cognitive engagement and deep learning while using different assessment modes. These findings add robust evidence to the program, which had already shown its efficacy in improving SRL competences in previous research, although in similar European cultural samples (Rosário et al., 2007; Rosário, Núñez et al., 2010).

The motivational dimension of SRL, namely self-efficacy, plays an essential role in the process of students' study (Fernández et al., 2013; Joët, Usher, \& Bressoux, 2011). Self-efficacy influences academic motivation, selection, and use of learning strategies in approaching academic tasks, therefore impacting on academic performance (Usher \& Pajares, 2008). Findings from the 'Letters from Gervase' program showed consistency across the four experimental groups, revealing the efficacy of this intervention tool in improving self-efficacy for SRL process, in spite of the different geographical and cultural settings.

Perceived instrumentality of SRL strategies characterizes the usefulness of these SRL strategies for students' study process. This motivational variable is critical for students' engagement in learning. First-year students can master the declarative knowledge of the SRL strategies and feel able to use these learning strategies, but unless these SRL strategies are perceived as being useful to improve their study process and the academic achievement, students are not likely to use them (Schunk \& Usher, 2011). The students' perception of the utility of these strategies is, therefore, closely related to the perceived demands of the learning context (Rosário et al., 2010). This close relation of the perceived utility with the academic context (e.g., teachers' approaches to teaching, typology of assessment followed, and typology of questions asked in class) may explain our results, since findings are not independent of the sample. Statistically significant group differences were found in the samples from Chile and Mozambique, but not in the European samples. Portuguese and Spanish academies are both facing a process of adaptation to educational paradigms related to the Bologna process, focusing, for example, on the promotion of students' autonomy and control of learning, and the use of new technologies in increasing participation in large classes (e.g., clickers), among other educational changes (Keeling, 2006). However, in many large lecture halls, this assumed educational change fostered by the Bologna process may not yet be a fact. Our results indicate that the participating European students do not report using learning strategies in responding to the demands of their academic tasks. These data pose an educational challenge to heads of departments and faculty. Future studies should consider investigating students' perception of academic demands and teachers' expectations in relation to the reported use of SRL strategies, and the setting-up of training programs in first-year lectures to promote approaches to student-centered teaching (Barratt, Hanlon, \& Rankin, 2011; Bone \& Reid, 2011).

The program 'Letters from Gervase' proved to be efficacious regardless of the country in which it was implemented. There are probably several reasons that can help to explain these results. The use of the narrative and the promotion of vicarious learning through a model similar to the students are emphasized. When discussing 
Gervase's university dilemmas, students can work on the strategic and self-regulated solutions for Gervase's, as well as their own, academic problems. The discussion of the SRL strategies in context (e.g., self-set goals, time management, and notetaking), of promoting personal and group reflection upon the contents of this academic story-tool, fosters the transfer of learning into their own experiences as students. The enrolled participants noted that their universities had no formal courses for promoting study and SRL competences where students can learn and discuss difficulties and challenges of their adaptation process to the academic university environment. University administrators and the heads of the departments could consider the organization of courses or workshops on SRL strategies based on the presented findings.

\section{Limitations and future research}

Despite the obtained positive results, future research should further investigate the long-term effects of this intervention; for example, analyzing the transfer of the SRL learning contents in the following semester by means of designs using repeated measures with follow-up assessments. Most of the variables assessing the efficacy of the program were collected through self-reports, which is an important limitation (Zimmerman, 2008) that can help explain the obtained effect size of the intervention. To tap the procedural nature of an SRL, future research should consider including measures of SRL as an event (Boekaerts \& Corno, 2005), including, for example, students' perceptions of the academic environment and diaries of their study process (Núñez et al., 2013). Lastly, the lack of perceived instrumentality of the SRL strategies indicates the need to improve the quality of the teaching process by enrolling teachers in a program aimed at improving the use of SRL in classrooms.

\section{Acknowledgment}

This work was partially supported by the Spanish Ministry of Education and Science (Project: SEJ2006-01518 and Project: EDU2010-16231).

\section{References}

Alexander, P.A. (2006). Psychology in learning and instruction. Upper Saddle River, NJ: Pearson Merril Prentice Hall.

Barratt, C., Hanlon, D., \& Rankin, M. (2011). Assessing the success of a discipline-based communication skills development and enhancement program in a graduate accounting course. Higher Education Research \& Development, 30, 681-695.

Biggs, J.B., \& Collis, K.F. (1982). Evaluating the quality of learning: The SOLO taxonomy. New York: Academic Press.

Boekaerts, M., \& Corno, L. (2005). Self-regulation in the classroom: A perspective on assessment and intervention. Applied Psychology: An International Review, 54, 199-231.

Bone, E., \& Reid, R. (2011). Prior learning in biology at high school does not predict performance in the first year at university. Higher Education Research \& Development, 30, 709-724.

Cleary, T.J., \& Chen, P.P. (2009). Self-regulation, motivation, and math achievement in middle school: Variations across grade level and math context. Journal of School Psychology, 47, 291-314.

Cohen, J. (1988). Statistical power analysis for the behavioral sciences. New York: Academic Press. 
Dignath, C., Buettner, G., \& Langfeldt, H. (2008). How can primary school students learn SRL strategies most effectively? A meta-analysis on self-regulation training programmes. Educational Research Review, 3, 101-129.

Fernández, E., Bernardo, A., Suárez, N., Cerezo, R., Núñez, J.C., \& Rosário, P. (2013). Predicción del uso de estrategias de autorregulación en educación superior [Prediction of use self-regulation strategies in higher education: An analysis at individual and context level]. Anales de Psicologia, 29(3), 865-875.

Greene, J.A., Hutchison, L., Costa, L.J., \& Crompton, H. (2012). Investigating how college students' task definitions and plans relate to self-regulated learning processing and understanding of a complex science topic. Contemporary Educational Psychology, 37, 307-320.

Hattie, J., Biggs, J., \& Purdie, N. (1996). Effect of learning skills interventions on student learning: A meta-analysis. Review of Educational Research, 66(2), 99-136.

Joët, G., Usher, E.L., \& Bressoux, P. (2011). Sources of self-efficacy: An investigation of elementary school students in France. Journal of Educational Psychology, 103, 649-663.

Keeling, R. (2006). The Bologna process and the Lisbon research Agenda: The European commission's expanding role in higher education discourse. European Journal of Education, 41, 203-223.

Mahrous, A.A., \& Ahmed, A.A. (2010). A cross-cultural investigation of students' perceptions of the effectiveness of pedagogical tools. Journal of Studies in International Education, 14, 289-306.

Núñez, J.C., Cerezo, R., González-Pienda, J.A., Rosário, P., Valle, A., Fernández, E., \& Suárez, N. (2011). Implementation of training programs in self-regulated learning strategies in Moodle format: Results of an experience in higher education. Psicothema, 23, 274-281.

Núñez, J.C., Rosário, P., Vallejo, G., \& González-Pienda, J.A. (2013). A longitudinal assessment of the effectiveness of a school-based mentoring program in middle school. Contemporary Educational Psychology, 38, 11-21.

Pintrich, P.R., \& Schunk, D.H. (2002). Motivation in education: Theory, research and applications (2nd ed.). Upper Saddle, NJ: Merrill/Prentice Hall.

Rosário, P., González-Pienda, J.A., Cerezo, R., Pinto, R., Ferreira, P., Lourenço, A., \& Paiva, O. (2010). Efficacy of the program 'Testas's (mis)adventures' to promote the deep approach to learning. Psicothema, 22(4), 828-834.

Rosário, P., Mourão, R., Núñez, J.C., González-Pienda, J.A., Solano, P., \& Valle, A. (2007). Evaluating the efficacy of a program to enhance college students' SRL processes and learning strategies. Psicothema, 19, 422-427.

Rosário, P., Núñez, J.C., \& González-Pienda, J.A. (2006). Comprometer-se com o estudar na Universidade: 'Cartas do Gervásio ao seu Umbigo' [Commit to study at the University: 'Letters from Gervais to his navel']. Porto: Almedina.

Rosário, P., Núñez, J.C., González-Pienda, J.A., Valle, A., Trigo, L., \& Guimarães, C. (2010). Enhancing self-regulation and approaches to learning in first-year college students: A narrative-based program assessed in the Iberian Peninsula. European Journal of Psychology of Education, 25, 411-428.

Schunk, D.H. (1996). Goal and self-evaluative influences during children's cognitive skill learning. American Educational Research Journal, 33, 359-382.

Schunk, D., \& Usher, E. (2011). Assessing self-efficacy for self-regulated learning. In B. J. Zimmerman \& D. Schunk (Eds.), Handbook of self-regulation of learning and performance (pp. 282-297). New York: Routledge.

Simpson, M.L., Hynd, C.R., Nist, S.L., \& Burrel, K.I. (1997). College academic assistance programs and practices. Educational Psychology Review, 9, 39-87.

Usher, E.L., \& Pajares, F. (2008). Self-efficacy for self-regulated learning: A validation study. Educational and Psychological Measurement, 68, 443-463.

Weinstein, C.E., Husman, J., \& Dierking, D. (2000). Self-regulation intervention with a focus on learning strategies. In M. Boekaerts, P. Pintrich, \& M. Zeidner (Eds.), Handbook of selfregulation (pp. 727-747). New York: Academic Press.

Zimmerman, B.J. (2002). Becoming a self-regulated learner: An overview. Theory into Practice, $41,64-70$.

Zimmerman, B.J. (2008). Investigating self-regulation and motivation: Historical, background, methodological developments, and future prospects. American Educational Research Journal, 45, 166-183. 
Zimmerman, B.J., \& Martínez-Pons, M. (1986). Development of a structured interview for assessing student use of self-regulated learning strategies. American Educational Research Journal, 23, 614-628.

Zimmerman, B.J., \& Schunk, D. (2011). Self-regulated learning and performance: An introduction and an overview. In B.J. Zimmerman \& D. Schunk (Eds.), Handbook of self-regulation of learning and performance (pp. 1-15). New York: Routledge. 